$\S=-1$

\title{
Slant Path Ka-Band rain attenuation statistics in equatorial Malaysia obtained using stratiform convective-synthetic storm technique
}

\author{
M. M. Yunus ${ }^{1,2 *}$, J. Din², S. L. Jong ${ }^{3}$, H. Y. Lam ${ }^{4}$ \\ ${ }^{1}$ Center of Telecommunication Research and Innovation, Faculty of Electronic and Computer Engineering, \\ Universiti Teknikal Malaysia Melaka, Hang Tuah Jaya, 76100 Durian Tunggal, Melaka, Malaysia \\ ${ }^{2}$ Wireless Communication Centre, Faculty of Electrical Engineering, Universiti Teknologi Malaysia, 81200 Skudai, Johor, Malaysia \\ ${ }^{3}$ Faculty of Electrical and Electronic Engineering, Universiti Tun Hussein Onn Malaysia, 86400 Batu Pahat, Johor, Malaysia \\ ${ }^{4}$ Faculty of Engineering Technology, Universiti Tun Hussein Onn Malaysia, 86400 Batu Pahat, Johor, Malaysia \\ *Corresponding author E-mail:mawar@utem.edu.my
}

\begin{abstract}
In the design of satellite communication link, rain attenuation statistics is essential information for system designer to realistically determine link availability and provide means to combat system degradation. Due to the limitation of available measured data in equatorial regions especially for high frequencies (Ka-band and above), the prediction model is the best way to obtain rain attenuation statistics. This paper presents statistical analysis of rain attenuation at Ka-band by applying the Stratiform Convective-Synthetic Storm Technique (SC-SST) model taking advantage from local weather features from rain rate time series. The study on seasonal and diurnal variability is also presented in this paper to provide good insight in the design and implementation of fade margin.
\end{abstract}

Keywords: rain attenuation; satellite communication system; Ka-band; equatorial region; Synthethic Storm Technique; SC-SST

\section{Introduction}

The satellite communication system providers are moving towards Ka- and higher frequency bands to meet higher data rates and bandwidth demands. One inherent drawback of Ka-band satellite systems is increase in signal distortion resulting from propagation effects, which mainly caused by the presence of rain. This effect is more severe in tropical/equatorial region with high rain intensity throughout the year [1][2]. Therefore, it is of great importance to perform comprehensive study on rain attenuation statistics particularly at high frequency bands in this region in order to provide high quality of services to the end user. However, tropical/equatorial regions are very much lacking of reliable measurement data due to the high cost of experimental setup and requires long periods of data collection [3]. Nevertheless, measured rain rate data are made available in many locations including in the tropics as the rain gauge are easier to install.

In this paper, we exploit the Stratiform Convective-Synthetic Storm Technique (SC-SST) [4] to provide reliable rain attenuation time series based on available rain rate time series measured at the location of interest. SC-SST model adapt a basic principle from the conventional Synthetic Storm Technique (SST) [8]. One of main advantage of these models are their abilities to retain local climate peculiarities when generates the rain attenuation induced on a hypothetical satellite link, thus rendering the model effectively worldwide [5][6]. Adding to that, SC-SST model introduced separation type of rain events (e.g. stratiform and convective events) in the calculation which lead to a better prediction of rain attenuation in tropical/equatorial region [7].
This paper is first briefly discussed on the basic principle of SC-SST model and parameter used in the estimation. The remainder of paper is structured as follows: The SC-SST prediction of rain attenuation at Ku-band compared against measurement data is discussed in Section III, which highlights the effectiveness of the prediction model. The analysis is then continue with rain attenuation estimation at Ka-band using SC-SST, as well as its seasonal and diurnal variation.

\section{Stratiform Convective-Synthetic Storm Technique (SC-SST)}

Stratiform and convective rain events have different space-time evolution that impacts radio wave propagation on different aspects Thus, proper discrimination on the rain events would definitely enhance the prediction model of rain attenuation. There are several classification techniques to discriminate the stratiform and convective rain available in the literatures [9]-[11]. The most direct method is by using different rain rate thresholds. In [12] the rain events is discriminated by a rain rate threshold of $20 \mathrm{~mm} / \mathrm{h}$ developed according to radar observation of the rainfall structure while the SAM model [13][7] used a threshold of $10 \mathrm{~mm} / \mathrm{h}$ based on an exponential shape of the rain spatial distribution. For comprehensive result, investigations on different rain rate thresholds for SCSST estimation is presented in this paper and eventually summarize the closed outcomes with the measured data in equatorial site.

Similar as SST, the SC-SST modelled vertical structure of the precipitation medium with two layers: a rain layer (layer $\mathrm{A}$ ) and 
melting layer (layer B) as shown in Fig 1. The effective path length, $L$ is calculated separately for different layers. In this case, the convective rain path, $L_{A}$ take into account the height of rain with $H=H_{A}$, whereas stratiform path length, $L_{B}$ considered the effect of melting layer height plus rain height, given as $H_{B}=h+$ $H_{A}$. Hence, the total link attenuation at location of interest can be obtained by summing the attenuation from each layer as given in the following expression:

$$
A\left(x_{o}\right)=k_{A} \int_{0}^{L_{A}} R^{\alpha_{A}}\left(x_{o}+\Delta x_{o}, \xi\right) d \xi+k_{B} r^{\alpha_{B}} \int_{L_{A}}^{L_{B}} R^{\alpha_{B}}\left(x_{o}, \xi\right) d \xi
$$

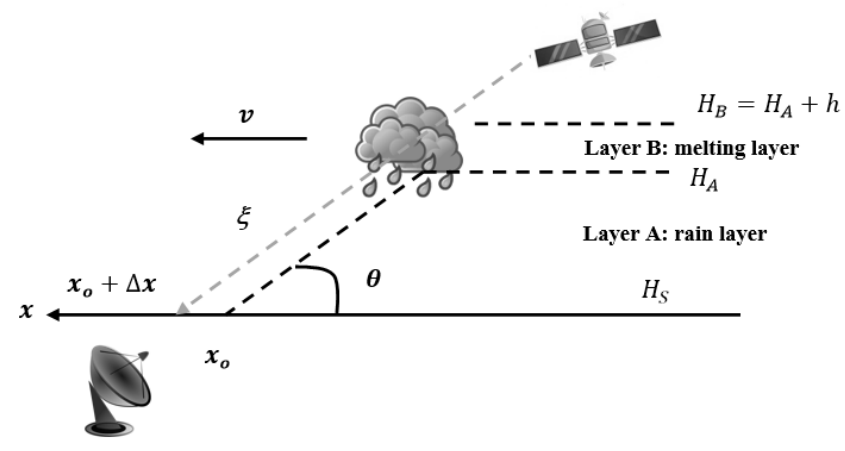

Fig. 1: Vertical structures of the two layers of precipitation and satellite link geometry

The simulation of rain attenuation is carried out by feeding the SC-SST with one minute integrated rain rate time series measured by rain gauge located in UTM-Johor Bahru for over a year [14]. The mean yearly wind intensity is set to be $v=6.5 \mathrm{~m} / \mathrm{s}$ which is extracted from the station of radiosonde located at Kuala Lumpur International Airport (KLIA), Sepang with the wind speed relative at pressure level of 700 hpa. Any other parameters such as $k$ and $\alpha$ constant values are as described in [4].

\section{Statistical Analysis of Rain Rate}

Equatorial region is considered to experience high precipitation rate with the majority of convective events evenly distributed throughout the year. Fig 2 shows the comparison of rain rate measured in Johor Bahru with measurement from disdrometer in Kuala Lumpur [4] that represents same equatorial climatic region, statistic of rain rate in Spinod'Adda [15] that represent temperate region and ITU-R P.837-6 [16] prediction model. The graph depicted measurement from Johor Bahru shows significantly high rain rate with $172 \mathrm{~mm} / \mathrm{h}$ at $0.001 \%$ of time. The good agreement between measurement in Kuala Lumpur and Johor Bahru gives clear indication of local climatic peculiarities within equatorial region even statistics in Kuala Lumpur consists longer duration of data. However, the distribution derived from ITU-R recommendations seem underestimate the measured statistics at $0.2 \%$ time and below. On the other hand, the remarkably different of statistics from Spino d'Adda with measured statistics clearly indicate that temperate region experience very much lower precipitation rate than in tropical/equatorial region with $130 \mathrm{~mm} / \mathrm{h}$ rain rate at $0.001 \%$ of time.

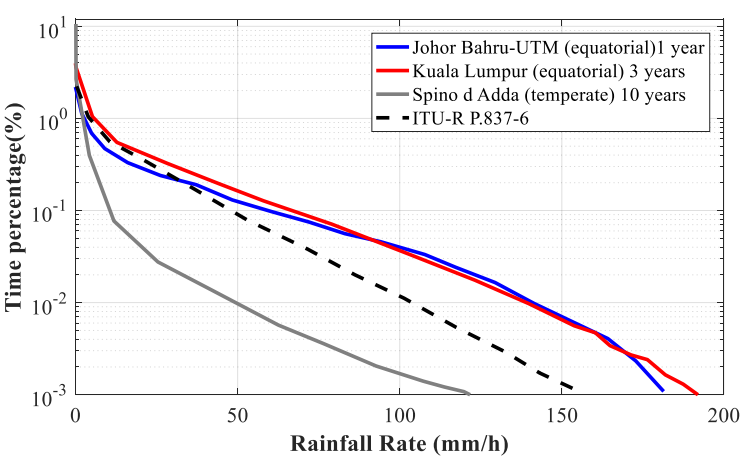

Fig. 2: Cumulative distribution of rain rate for Johor Bahru, Kuala Lumpur, Spino d'Adda and ITU-R prediction.

\section{Statistical Analysis of Rain Attenuation}

Cumulative distribution of rain attenuation at $\mathrm{Ku}$-band $(12 \mathrm{GHz})$ estimated by SC-SST model for different discrimination thresholds of stratiform and convective rain events is compared with measurement data in Johor Bahru as shown in Fig 3. Three rain rate thresholds, $R_{\text {th }}$ are chosen to investigate the precisely separation between the two events. Rain rate threshold of $10 \mathrm{~mm} / \mathrm{h}$ seems provide the closeness distribution to the measured data with $0.91 \mathrm{rms}$ errors. Higher threshold of rain rate might reduce the number of convective events that usually occurs in short duration which leads to the slight overestimation of the statistics. For completeness, statistics of rain attenuation predicted by ITU-R P.61810 [17] is also presented in the graph which clearly shows underestimation of ITU-R prediction with the measured and SC-SST distributions.

Rain rate threshold of $10 \mathrm{~mm} / \mathrm{h}$ is then used in the estimation of rain attenuation using SC-SST for Ka-band $(20 \mathrm{GHz})$ and plotted in Fig 4. The ITU-R prediction shows overestimation to up to $0.1 \%$ of time and underestimates at lower percentage of time. The worst month statistic (consist of distribution from month December) estimated by SC-SST is also presented in the graph. Interestingly, the comparison between worst month statistics predicted by ITU-R P.841 [18] with SC-SST is in well agreement from $0.1 \%$ of time and below, but overestimates at high percentage of time. The discrepancy of these results is better to validate with the results using experimental data which what we are lacking of. Table 1 summarizes the attenuation values exceeded at $0.1 \%$ and $0.01 \%$ of time for rain attenuation predicted by SC-SST and ITU-R.

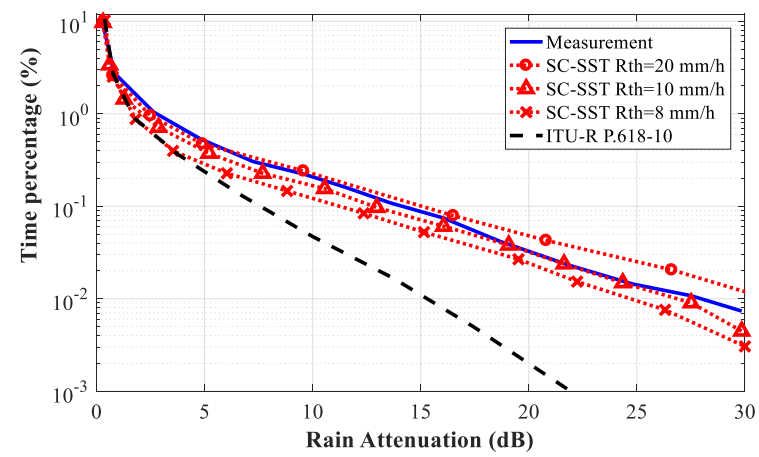

Fig. 3: Comparison of cumulative distribution of rain attenuation at $\mathrm{Ku}$ Band $(12 \mathrm{GHz})$ predicted using SC-SST at different discrimination thresholds with measured distribution in Johor Bahru and ITU-R prediction. 


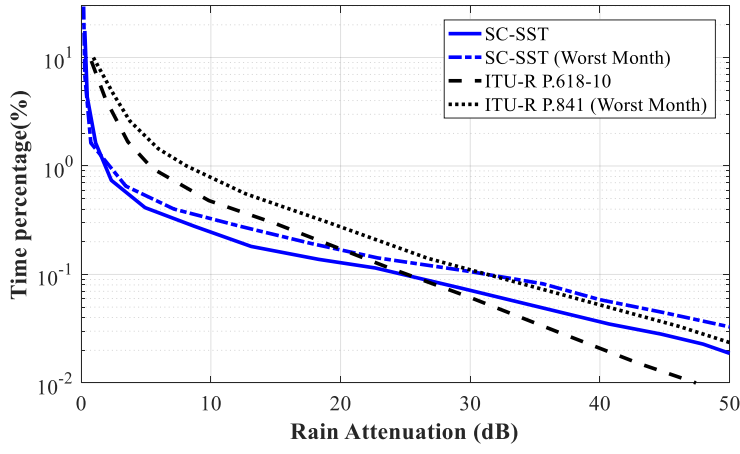

Fig 4: Annual and Worst-month Rain Attenuation Statistics at Ka-Band $(20 \mathrm{GHz})$ predicted using SC-SST in comparison with ITU-R prediction..

Table 1: Comparison of cumulative statistics of rain attenuation at KaBand $(20 \mathrm{GHz})$

\begin{tabular}{l|c|c}
\hline \multirow{2}{*}{ Model } & \multicolumn{2}{|c}{$\begin{array}{c}\text { Attenuation exceeded for specific \% of } \\
\text { time }\end{array}$} \\
\cline { 2 - 3 } & $0.1 \%$ & $0.01 \%$ \\
\hline SC-SST & 24.2 & 58.3 \\
ITU-R P.618-10 [16] & 25 & 47.8 \\
\hline
\end{tabular}

\section{Seasonal and Diurnal Variation of Rain At- tenuation}

The study on seasonal and diurnal statistical fluctuations is also of great interest to look into details fades tendency at different time throughout the year. Seasonal variation of rain attenuation is observed by classifying the cumulative distribution based on monsoon season as shown in Fig 5 (a). The Inter-Monsoon season shows highest attenuation amongst all seasons. Note that during this season, the gradual process begins where the monsoon wind is reversed and convective events increases more often. The NorthEast Monsoon (Dec-March) follows the yearly statistics during the complete percentage of the time interval closely. On the other hand, the Southwest Monsoon season (June-Sept) exhibits the lowest seasonal rain attenuation with significance difference at the interval around $0.02 \%$ to $0.2 \%$ of time. During this season, the weather becomes relatively more stable which causes less intense convective development.

Besides seasonal variations, the analysis on hourly basis is also useful for system operators to take into considerations in the design of fade margin. This is particularly crucial in tropical/equatorial region that experiences significantly different rain rate at different times of the day [3]. To this aim, the 24 hours is divided in 4 time intervals of 6 hour duration and the probability of rain attenuation exceedance is then calculated for each segment as shown Fig 5 (b). The high attenuation is likely to occur in the past afternoon which indicates higher fade margin is required in the afternoon hours for same availability than the other times of the day. While, the rain attenuation probability is lowest during morning time (0 to $6 \mathrm{am}$ ) with fade margin of $16 \mathrm{~dB}$ for $99.9 \%$ link availability.

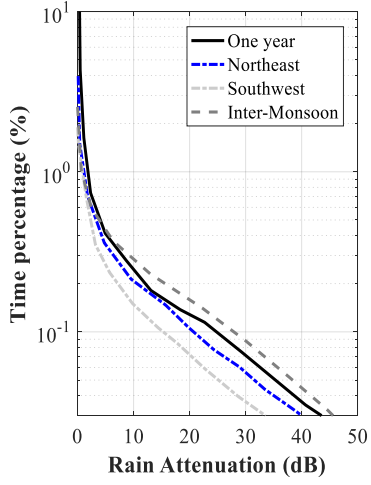

(a)

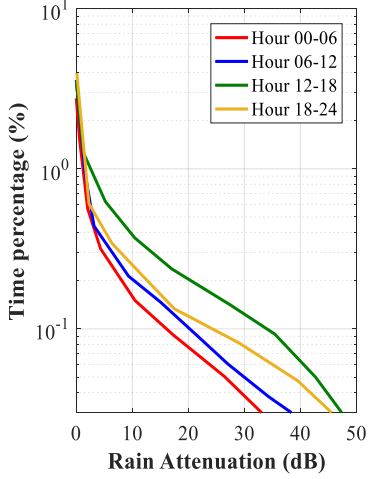

(b)
Fig. 5: Rain Attenuation Variability (a) Seasonal basis (b) Diurnal basis

\section{Conclusion}

This paper has presents statistical analysis of rain attenuation for Ka-band Earth-space link in equatorial region by means of SCSST estimation. Proper selection of rain rate threshold for SC-SST model would definitely lead to a better estimation for rain attenuation. The discrepancy of SC-SST and ITU-R prediction indicates the necessity to validate the results using measured data. Lastly, the seasonal and diurnal statistics depicts the variability of rain attenuation in specific time throughout the year. This information is useful for system designers in the design and implementation of Fade Mitigation Techniques (FMTs) to improve link outage.

\section{Acknowledgement}

The authors are grateful to UTM funded under Hi-COE Research Grant Vot. No. R.J130000.7823.4J221 and UTeM for sponsoring this work.

\section{References}

[1] A. F. Ismail, and P. A. Watson, "Characteristics of Fading and Fade Countermeasures on a satellite-Earth Link in Equatorial Climates,' in IEEE Proceeding, vol 147,no 5, pp.369-373, 2000.

[2] M. C. Ketswal, R. Joshi, D. Rawat and S. Sambyal, "Microwave Attenuation Studies Impacted by Rain for Communication Links Operatingat Tropical Region: A Survey," International Journal of Advanced Trends in Computer Science and Engineering (IJATCSE), vol. 4 no.1, pp. 05 - 14, 2015.

[3] S.L. Jong, H.Y. Lam, J. Din, M. D'Amico, "Investigation of KaBand Satellite Communication Propagation in Equatorial Regions," Journal of Engineering and Applied Sciences, vol 10, no 20, pp. 9795-9799, 2015.

[4] H. Y. Lam, L. Luini, J. Din, C.Capsoni, A. D. Panagopouloos, "Investigation of Rain Attenuation in Equatorial Kuala Lumpur" IEEE Antennas and Wireless Propagation Letters, vol.11, pp.1002-1005, 2012.

[5] S. Kenellopoulos, A. D. Panagopoulos, E. Matricianni, J.D. Kenellopoulos, "Annual and Diurnal Slant Path Rain Attenuation Statistics in Athens obtained with Synthetic Storm Technique," IEEE Trans Antennas Propag, vol. 54(8), pp. 2357-2364, 2006.

[6] R. J. Acosta et al., "Slant Path Attenuation and Microscale Diversity Gain Measured and Predicted in Guam with the Synthetic Storm Technique," in 7th European Conference on Antennas and Propagation (EuCAP), 8-12 April 2013, Gotenburg, pp. 61-64.

[7] C. Capsoni, L. Luini, A.Paraboni, C. Riva and A. Martelucci, "A new prediction model of rain attenuation that separately accounts for stratiform and convective rain," IEEE Transactions on Antennas and Propagation, vol 57 (1).pp. 196-204, 2009.

[8] E. Matricianni, "Physical-Mathematical model of the dynamics of rain attenuation based on rain rate time series and two layer vertical structure of precipitation," Radio Science, vol. 31, pp. 281-295, 1996. 
[9] A. Tokay and D. A. Short, "Evidence from tropical raindrop spectra of the origin rain from stratiform versus convective cloudes," $J$. Appl. Meteor. , vol 35, no 3, pp.355-371, 1996.

[10] M. Steiner, R. A . House, and S. E. Yuter, "Climatological Characterization of Three-Dimensional Storm Structure from Operational Radar and Rain Gauge Data," Journal of Applied Meteorology and Climatology, vol. 34, pp. 1978-2007, 1995

[11] K. Badron, et al, "Classification of Precipitation Types Detected in Malaysia,"

[12] Leitao M. J. and Watson P. A., "Method for prediction of attenuation on earth space links based on radar measurements of the physical structure of rainfall," in Proc. Inst. Elect. Eng., vol 133(4), pp 429-440, 1996.

[13] Stutzman W. L. and Dishman W. K. "A simple model for the estimation of rain-induced attenuation along earth-space paths at millimeter wavelengths," Radio Sci., vol 17(6), pp 1465-1476, 1982.

[14] S. L. Jong, Rain fade dynamics characteristics for Ku-band satellite communication systems in Malaysia, PhD. Thesis, Fac. Of Electrcial Eng., Universiti Teknologi Malaysia, 2015.

[15] C. Riva, "Seasonal and Diurnal Variations of Total Attenuation Measured with the Italsat Satellite at Spinod'Adda at 18.7, 39.6 and $49.5 \mathrm{GHz}$," International Journal of Sat. Comm and Networking, vol.22, pp.449-476, 2004.

[16] Characteristics of Precipitation for Propagation Modeling.ITU-R P.837-6, Geneva, 2012.

[17] Propagation Data and Prediction Methods required for the Design of Earth-space Telecommunication Systems. ITU-R P.618-12, 2016.

[18] Conversion of Annual Statistics to Worst-MonthStatistics. ITU-R P.841-3, 2003. 